О корреляционных взаимосвязях некоторых

факторов сердечно-сосудистого риска и дисрегуляции артериального давления у лиц молодого возраста

М.Е. Евсевьева*, Г.П. Никулина, О.В. Сергеева, М.В. Батурина, М.В. Ростовцева, 3.Н. Найманова, А.Ю. Подушинский

ГОУ ВПО «Ставропольская государственная медицинская академия Федерального агентства по здравоохранению и социальному развитию». Ставрополь, Россия

\title{
Correlation between some cardiovascular risk factors and blood pressure dysregulation in young people
}

M.E. Evsevyeva*, G.P. Nikulina, O.V. Sergeeva, M.V. Baturina, M.V. Rostovtseva, Z.N. Naymanova, A.Yu. Podushinskiy

Stavropol State Medical Academy. Stavropol, Russia

Цель. Оценить наличие корреляционных взаимосвязей показателей офисного и амбулаторного артериального давления (АД) с некоторыми факторами сердечно-сосудистого риска (ССР) у практически здоровых лиц молодого возраста и у лиц с дисрегуляцией АД.

Материал и методы. Обследованы 234 студента СтГМА обоего пола в возрасте 18-23 лет (средний возраст 21,4 $\pm 0,2$ лет) - 73 юношей и 161 девушка. Проводились опрос по стандартной анкете для выяснения семейного анамнеза, наличия вредных привычек, определение антропометрических параметров, анкетирование с целью выявления психологических расстройств, измерение АД традиционным и мониторинговым методами.

Результаты. Факторы риска (ФР) сердечно-сосудистых заболеваний (ССЗ) достаточно широко представлены среди обследованных, причем среди юношей их распространенность в 2-3 раза выше, чем среди девушек. Артериальная гипертензия (АГ) представлена в виде лабильных форм АГ - изолированной офисной и скрытой АГ. Корреляционный анализ показателей офисного и амбулаторного АД с некоторыми факторами ССР, показал, что у лиц с изолированной офисной и скрытой АГ выявляется большее количество достоверных ассоциаций между обозначенными показателями и возрастает сила этих связей.

Заключение. Наличие у молодого контингента достаточно сильной корреляционной связи между различными формами лабильной АГ с основными факторами ССР обосновывает необходимость включения в гр. риска лиц с указанными формами повышения давления, что позволит оптимизировать существующие программы по укреплению здоровья студентов.

Ключевые слова: факторы риска, молодой возраст, суточное мониторирование артериального давления, сердечно-сосудистый риск.

Aim. To assess the correlations between office and ambulatory blood pressure (BP) levels and some cardiovascular risk factors (RFs) in healthy young people and young people with BP dysregulation.

Material and methods. In total, 234 male and female students of the Stavropol State Medical Academy were examined (73 men, 161 women; age 18-23 years, mean age $21,4 \pm 0,2$ years). The standard questionnaire included items on family history and behavioural risk factors. The examination also included anthropometry, psychological symptom questionnaire survey, office BP measurement, and ambulatory BP monitoring.

Results. RFs of cardiovascular disease (CVD) were widely prevalent in the students examined, with the rates in males being 2-3 times higher than in females. Arterial hypertension (AH) was presented by its labile forms isolated office $\mathrm{AH}$ and masked AH. Participants with these AH forms, compared to healthy students, were characterized by a greater number and greater strength of the correlations between office or ambulatory BP parameters and some CVD RFs.

(сКоллектив авторов, 2011

e-mail: evsevieva@mail.ru

Тел.: 89283154687

[Евсевьева М.Е. (*контактное лицо) - профессор кафедры внутренних болезней №2, Никулина Г.П. - доцент кафедры Сергеева О.В. - ассистент кафедры, Батурина М.В. - аспирант кафедры, Ростовцева М.В. - практический врач, соискатель, Найманова 3.Н. - практический врач, соискатель, Подушинский А.Ю. - практический врач, соискатель]. 
Conclusion. The association between labile AH and leading CVD RFs in young people points to the need for regarding individuals with labile $\mathrm{AH}$ as a risk group and for optimising preventive programs in students.

Key words: Risk factors, young age, 24-hour blood pressure monitoring, cardiovascular risk.

Одним из основных направлений развития здравоохранения в настоящее время является формирование эффективных мер профилактики сердечно-сосудистых заболеваний (СС3), на долю которых приходится наиболее высокий процент инвалидизации и смертности среди населения большинства высокоразвитых стран [8]. Основой для разработки мер по сохранению здоровья является концепция факторов риска (ФР) [2,6,7]. Согласно рекомендациям, утвержденным Всероссийским научным обществом кардиологов (2007), к основным ФР атеросклероза относятся: артериальная гипертензия (АГ), возраст, курение, отягощенная наследственность $(\mathrm{OH})$, дислипидемия (ДЛП), избыточная масса тела (ИзМТ), депрессия (Д). Ведушая роль при этом принадлежит повышенному артериальному давлению (АД), которое вносит основной вклад в структуру смертности населения Российской Федерации [1].

В многочисленных исследованиях доказано наличие взаимосвязи уровня АД с другими ФР ССЗ $[4,5,9,10]$. Однако эти исследования выполнены при участии пациентов с различными стадиями гипертонической болезни, тогда, как известно, что факторы сердечно-сосудистого риска (ССР) присутствуют у практически здоровых лиц уже в молодом возрасте и даже в детстве, т.е. задолго до клинической манифестации того или иного ССЗ. Поэтому представлялось практически важным оценить наличие корреляционных взаимосвязей показателей офисного и амбулаторного АД с факторами ССР у практически здоровых лиц молодого возраста и у лиц с дисрегуляцией АД, т.е. на доклинической стадии АГ.

\section{Материал и методы}

Обследованы 234 студента СтГМА обоего пола в возрасте 19-23 лет (средний возраст 21,4 $\pm 0,2$ лет) - 73 юноши и 161 девушка.

Критериями включения в исследование были возраст 18-25 лет, обучение в высшем учебном заведении, согласие обследуемых на прохождение всех этапов исследования. Критерии исключения: наличие на момент обследования острого или обострения хронических заболеваний, неслучайный характер обращения обследуемого для проведения исследования.

Обследование включало: опрос по стандартной анкете для выяснения паспортных данных, семейного анамнеза, наличия вредных привычек, определение антропометрических параметров, анкетирование по госпитальной шкале тревоги и депрессии (HADS), измерение АД традиционным и мониторинговыми методами.

Суточное мониторирование АД (СМАД) проводили с помощью портативного аппарата МД-01 «Дон» (г. Москва) амбулаторно в режиме «типичного рабочего дня», продолжалось в среднем $24 \pm 1,5$ часа. Интервал между измерениями АД составлял 30 мин в период бодрствования и 60 мин во время сна. Все пациенты во время исследования заполняли индивидуальные дневники, где отражали физическую активность (ФА), умственную и эмоциональную нагрузки в дневное время, время отхода ко сну и подъем, а также качество сна. При этом анализировали 30 показателей. Критерием верификации АГ при СМАД было среднесуточное АД $\geq 125-130 / 80$ мм рт.ст., АД $\geq 135 / 85$ мм рт.ст. днем (д) и АД $\geq 120 / 70$ мм рт.ст. ночью (н) по рекомендациям ESC/ESH 2007, BНОК (2008).

Измерение АД непрямым методом Н.С. Короткова (офисное измерение) производили на обеих руках трижды с 5-минутным интервалом в положении сидя в удобной позе. Среднее из 2-х последних измерений принимали в качестве уровня систолического и диастолического АД (САД и ДАД). Для оценки офисного АД использовали классификации, рекомендованные ВНОК, 2008.

Сопоставление результатов офисного и амбулаторного АД давало возможность выделить лабильную АГ в виде двух ее форм - изолированной офисной (ИОАГ) и скрытой АГ. Заключение об ИОАГ делали на основании трехкратно зафиксированного повышенного АД при офисном измерении и нормальных его среднесуточных значениях. Скрытую АГ диагностировали при нормальных величинах офисного АД и повышенном АД по результатам СМАД. Лица с нормальным АД, как при офисном, так и при амбулаторном его измерении, относились к категирии стабильной нормотонии. Случаи повышения АД по результатам двух методов классифицировались как стабильная АГ.

Оценка ФР СС3 осуществлялась в соответствии с Национальными рекомендациями по диагностике и лечению ДЛП (ВНОК, 2007). Наследственность обследуемого считали отягощенной, если имелись указания на развитие ранних ССЗ у близких родственников $(<65$ лет у женщин, $<55$ лет у мужчин). Курившим считался человек, выкуривающий хотя бы 1 сигарету в день в течение последнего месяца и более или бросивший курить менее чем 1 год назад. Для характеристики индекса массы тела (ИМТ) использовали классификацию ВО3 (1998), в которой степень (ст.) избытка или недостатка МТ оценивается по индексу Кетле (масса в кг/рост в м²). Выявление и оценка тяжести Д и тревоги (Т) проводились с помощью шкалы HADS. При этом выделяли три области значений суммарного показателя: 0-7 баллов «норма», 8-10 баллов - «субклинически выраженная тревога/депрессия», $\geq 11$ баллов - «клинически выраженная тревога/депрессия».

Результаты обработаны с помощью пакета анализа STATISTICA, версия 6,0. Для сравнения относительных величин применялся критерий $\chi^{2}$. Для характеристики взаимосвязи двух признаков использовали коэффициент корреляции рангов Спирмена или Кенделла. Ранговую корреляцию по Спирмену применяли для оценки взаимосвязи количественных признаков. Ранговую корреляцию по Кенделлу применяли для оценки взаимосвязи двух порядковых признаков или порядкового и количественного признаков. Различия считали достоверными при $\mathrm{p}<0,05$. 


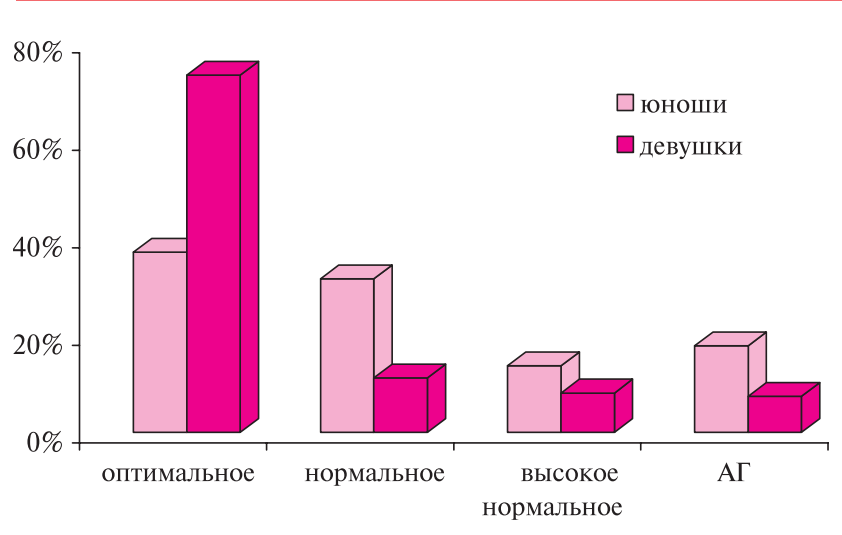

Puc. 1 Распределение студентов по уровню офисного АД.

\section{Результаты}

Распространенность некоторых факторов ССР среди студенческой молодежи

$\underline{A \Gamma}$. Согласно полученным данным, в обследованном коллективе студентов по данным офисного измерения уровень АД, соответствующий оптимальному, имели $37 \%(\mathrm{n}=27)$ юношей и $73,3 \%(\mathrm{n}=118)$ девушек. Нормальное АД определялось у $31,5 \%(n=23)$ и $11,2 \%(n=18)$ студентов соответственно. Высокое нормальное - у 13,7\% $(\mathrm{n}=10)$ юношей и $8,1 \%(\mathrm{n}=13)$ девушек. АГ была зарегистрирована у $17,8 \%(n=13)$ юношей и 7,4\% $(\mathrm{n}=12)$ девушек. Таким образом, оптимальное АД в 2 раза чаще встречалось у девушек, а нормальное и высокое нормальное, наоборот, в 3 и 2 раза чаще у юношей (рисунок 1).

В соответствии с результатами СМАД, нормальные среднесуточные, среднедневные и средненочные значения САД и ДАД имели $80,8 \%(\mathrm{n}=59)$ юношей и 91,3\% (n=143) девушек. Артериальная гипотония зарегистрирована у 1 девушки $(0,6 \%)$. Амбулаторная АГ выявлялась у $19,2 \%(\mathrm{n}=14)$ и $8,1 \%$ $(n=13)$ студентов, соответственно.

По результатам комплексной оценки АД, обследуемые распределились следующим образом: $77,8 \%$ студентов соответствовали категории стабильной нормотонии. Все случаи повышенного АД при традиционном его измерении как у юношей, так и у девушек не были подтверждены результатами СМАД и поэтому классифицировались как ИОАГ

\begin{tabular}{|c|c|c|}
\hline 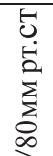 & $\begin{array}{l}\text { Скрытая } \\
\text { АГ } \\
11,5 \%\end{array}$ & $\begin{array}{l}\text { Стабильная } \\
\text { АГ } \\
0,0 \%\end{array}$ \\
\hline 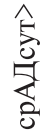 & $\begin{array}{l}\text { Стабильная } \\
\text { нормотония } \\
77,8 \%\end{array}$ & $\begin{array}{l}\text { Офисная } \\
\text { АГ } \\
10,7 \%\end{array}$ \\
\hline & \multicolumn{2}{|c|}{ Офисное АД>140/90мм рт.ст. } \\
\hline
\end{tabular}

Puc. 2. Варианты распределения по результатам двух методов измерения АД.

- 10,7\% (n=25). Частота выявления скрытой АГ составила $11,5 \%(\mathrm{n}=27)$ (рисунок 2).

Оценка распространенности некоторых других ФР СС3 показала, что ОН имела место у каждого 2-го студента. Курившими на момент опроса оказались 26\% молодых людей и $11,2 \%$ девушек. ИзМТ определялась у $19 \%$ юношей и 5,6\% девушек. Результаты проведенного психологического тестирования показали, что практически у 7\% обследованных имело место наличие клинически выраженной Т/Д (таблица 1).

Таким образом, основные модифицируемые ФР, такие как ИзМТ, курение и повышение АД среди юношей встречались в 3-5 раз чаще, чем среди девушек. Уже в молодом возрасте представители мужского пола оказываются в более неблагоприятном положении в плане уровня ССР, что в конечном итоге приводит к последствиям в виде самого большого в мире разрыва в ожидаемой продолжительности жизни российских женщин и мужчин [1]. По данным Государственного доклада о состоянии здоровья населения России, среди умерших в трудоспособном возрасте мужчины составляют $\sim 80 \%$. Уровень мужской смертности в 4 раза выше уровня женской и в 2-4 раза выше, чем в экономически развитых странах. Совокупность этих данных указывает на необходимость осуществления превентивных мероприятий в первую очередь среди лиц мужского пола, причем уже в молодом возрасте.

Таблица 1

Распространенность отдельных ФР СС3 среди обследованных лиц молодого возраста

\begin{tabular}{|c|c|c|c|c|c|c|}
\hline \multirow[t]{3}{*}{ Факторы риска } & \multicolumn{2}{|c|}{ Юноши } & \multicolumn{2}{|c|}{ Девушки } & \multicolumn{2}{|c|}{ Bce } \\
\hline & \multicolumn{2}{|c|}{$\mathrm{n}=73$} & \multicolumn{2}{|c|}{$n=161$} & \multicolumn{2}{|c|}{$\mathrm{n}=234$} \\
\hline & Абс & отн & абс & отн & абс & отн \\
\hline Офисное АД $\geq 140 / 90$ мм рт. ст. & 13 & $17,8^{*}$ & 12 & 7,4 & 25 & 10,7 \\
\hline Амбулаторное АД $\geq 125 / 80$ мм рт .ст & 14 & $19,2^{*}$ & 13 & 8,1 & 27 & 11,5 \\
\hline ИМТ $\geq 25 \mathrm{\kappa г} / \mathrm{M}^{2}$ & 14 & $19,2^{*}$ & 9 & 5,6 & 23 & 9,8 \\
\hline $\mathrm{OH}$ & 34 & 46,6 & 86 & 53,4 & 120 & 51,3 \\
\hline Курение & 19 & $26^{*}$ & 18 & 11,2 & 37 & 15,8 \\
\hline Т/Д & 3 & 4,1 & 13 & 8,1 & 16 & 6,8 \\
\hline
\end{tabular}

Примечание: *-p $<0,05$ в сравнении с девушками. 
Ассоциации офисного АД с основными ФР СС3. У юношей и девушек со стабильно нормальным уровнем АД между показателями офисного АД и рассматриваемыми факторами ССР достоверные корреляционные связи отсутствовали $(\mathrm{p}>0,05)$.

Корреляционный анализ, проведенный при дисрегуляции АД, выявил наличие некоторых достоверных взаимосвязей $(p<0,05)$. У юношей со скрытой АГ определялась корреляционная зависимость между САД и уровнем Т $(\mathrm{r}=0,94)$, а также ДАД и ИМТ $(\mathrm{r}=-0,78)$. У девушек с ИОАГ и скрытой АГ достоверные корреляционные связи выявлены между ОН и САД ( $\mathrm{r}=0,81 ; \mathrm{r}=0,77$ соответственно). Отмечены ассоциации ДАД с ИМТ у девушек со скрытой АГ $(\mathrm{r}=-0,8)$.

Таким образом, следует отметить, что у молодых людей с признаками дисрегуляции АД для показателей, характеризующих офисного АД, и некоторыми ФР ССЗ присутствовали корреляционные связи, которых не было у их сверстников со стабильно нормальным АД. Статистически значимые ассоциации определены для таких ФР, как ОН, ИМТ и уровень Т.

Ассоциации показателей амбулаторного АД и основных ФР ССЗ. Проанализированы корреляционные взаимоотношения между изученными факторами ССР и показателями суточной динамики АД. Для некоторых из них обнаружены статистически достоверные взаимосвязи с обозначенными $\Phi P(\mathrm{p}<0,05)$.

У юношей со стабильной нормотонией были обнаружены взаимосвязи умеренной силы между ИМТ и вариабельностью (Вар) ДАДн $(\mathrm{r}=0,56)$, а также числом внешних стигм дизэмбриогенеза и пульсового давления (ПД)д $(\mathrm{r}=0,65)$.

У юношей с ИОАГ наличие достоверных ассоциаций между ОН и показателями суточного профиля АД определено для ДАД $24(\mathrm{r}=0,75)$, ДАДд $(\mathrm{r}=0,75)$, индекса времени (ИВ) ДАДд $(\mathrm{r}=0,76) ; \mathrm{y}$ юношей со скрытой АГ такими показателями были среднее гемодинамическое давление в течение ночи (СГДн) $(\mathrm{r}=0,7)$, ПДд $(\mathrm{r}=0,6)$, ВарСАДд $(\mathrm{r}=0,65)$. У юношей со скрытой АГ между показателями, характеризующими нагрузку САД в дневное и в ночное время, и уровнем Д обнаружена достоверная сильная положительная связь $(\mathrm{r}=0,8$ и 0,87 соответственно). Связь факта курения с САДн также была достоверной и прямой $(\mathrm{r}=0,63)$.

Для девушек со стабильной нормотонией выявленные взаимосвязи ОН с показателями СМАД имели слабую силу: ДАД $24(\mathrm{r}=0,21)$, ДАДд $(\mathrm{r}=0,22)$, ИВДАДд $(\mathrm{r}=0,27)$, ВарСАДд $(\mathrm{r}=0,33)$, ВарДАДд $(\mathrm{r}=0,22)$.

У девушек с ИОАГ ОН коррелировала с некоторыми показателями суточного профиля АД, причем сила этой связи была выраженной: ДАД 24 (r=0,89), ВарДАДн $(r=0,81)$. Сильная связь определялась также между ИМТ и ДАД $24(\mathrm{r}=-0,86)$, ПДд $(\mathrm{r}=0,86)$, ИВСАДд $(\mathrm{r}=0,86)$ и ИВДАДд $(\mathrm{r}=-0,86)$.

Среди девушек со скрытой АГ достоверные корреляционные связи определены для ИМТ с $\mathrm{CAД}_{24}(\mathrm{r}=0,73)$, ДАД $24 \quad(\mathrm{r}=-0,8), \quad$ ПД $24 \quad(\mathrm{r}=0,8)$, ИВСАДД $(\mathrm{r}=-0,8)$. Уровень Д среди девушек со скрытой АГ продемонстрировал наличие взаимосвязи умеренной выраженности: с ДАДн $(\mathrm{r}=0,5), \mathrm{c}$ СГД $(\mathrm{r}=0,48)$, с СИСАД $(\mathrm{r}=-0,56)$, СИДАД $(\mathrm{r}=$ $-0,69)$, с ИВДАД н $(\mathrm{r}=0,61)$.

Таким образом, проведенный корреляционный анализ между показателями, характеризующими уровень АД в течение сут, и факторами ССР показал, что у лиц с любым вариантом лабильной АГ в сравнении со стабильной нормотонией выявляется большее количество достоверных ассоциаций между обозначенными показателями и возрастает сила этих связей.

\section{Обсуждение}

Представленные результаты свидетельствуют о наличии гендерных особенностей в распределении лиц молодежной популяции по уровню офисного АД. Отнесение молодого человека к категориям оптимального, нормального, высокого нормального или АГ в значительной степени зависит от половой принадлежности. Это предполагает необходимость доработки нормативов АД у молодежи с учетом пола.

В соответствии с полученными данными оказалось, что все случаи АГ, выявленной при обычном измерении (10,7\%), оказались случаями ИОАГ. Еще у $11,5 \%$ обследованных студентов регистрировалось неопределяемое традиционным способом повышение АД, которое обозначается как скрытая АГ. В целом у 22,2\% представителей учащейся молодежи имелись различные формы лабильной АГ. В изученной выборке случаи стабильной АГ, которая бы характеризовалась подъемом АД в присутствии медработника и без него в течение дня или ночи, отсутствовали.

Несмотря на то, что информация о возможной динамике указанных вариантов АГ ограничена, имеются данные о повышенном ССР у их носителей, что свидетельствует о том, что эти формы АГ могут иметь определенное клиническое значение.

В настоящем исследовании было показано, что принадлежность молодого человека к одному из выявленных вариантов АГ сочетается с большей распространенностью ФР ССЗ. Чаще всего присутствовали ОН и ИзМТ. Распространенность сочетания ФР в указанных категориях также была выше. Как среди юношей, так и среди девушек число лиц без ФР было наибольшим при стабильной нормотонии $(\mathrm{p}<0,05)$. Комбинация 2 ФР чаще определялась при офисной и скрытой АГ. А 3 ФР отмечены только среди юношей с различными вариантами АГ. 
Все сказанное выше, предполагает наличие более высокого относительного риска у лиц со скрытой и ИОАГ по сравнению с представителями стабильной нормотонии, а при проецировании имеющегося профиля рисков на зрелый возраст, можно предполагать более высокий абсолютный риск у этих лиц.

Получены данные о наличии у практически здоровых лиц молодого возраста корреляционных взаимосвязей ОН с некоторыми показателями суточного профиля АД. У девушек со стабильной нормотонией ассоциации ОН с ДАД 24, , ИВДАДд, ВарСАДд, ВарДАДд имели слабую силу. Связь ОН с показателями суточного профиля АД при дисрегуляции АД была сильной и имела прямую направленность.

Значение указанного ФР в молодежной популяции для формирования гр. риска по развитию АГ отмечено в ряде исследований. По данным литературы, повышенное АД выявляется в 3 раза чаще у подростков и лиц молодого возраста из семей, члены которых страдали АГ, чем у пациентов из семей, где такие случаи отсутствовали. Поэтому, являясь немодифицируемым, но легко выявляемым ФР, ОН может выступать в качестве критерия для стратификации гр. диспансерного наблюдения у молодежи с обязательным проведением им необходимого обследования для выявления АГ.

ИзМТ достоверно чаще имела место у юношей с любым вариантом АГ и девушек с ИОАГ. Проведенный корреляционный анализ показал, что у них между ИМТ и показателями офисного и амбулаторного АД существуют взаимосвязи, чаще с прямой направленностью, что подтверждается данными литературы о значении ИзМТ как ФР CC3.

Согласно данным ВО3, 16,8\% женщин и 14,9\% мужчин на планете имеют ИзМТ. Принципиально важен тот факт, что у значительной части пациентов ожирение (Ож) служит предиктором развития метаболического синдрома (МС), а кардиометаболические эффекты адипоцитов могут ускорять развитие сердечно-сосудистого континуума на всех его этапах. Связь между Ож и АГ была убедительно доказана во многих исследованиях. Фремингемское исследование показало, что у лиц среднего возраста с ИзМТ вероятность развития АГ на $50 \%$ выше, чем среди тех, кто не страдает Ож. Увеличение ИМТ сопровождалось достоверным повышением САД и ДАД, причем на каждые лишние 4,5 кг веса приходилось увеличение САД на 4,4 мм рт. ст. у мужчин и на 4,2 мм рт. ст. у женщин.

Отрицательная корреляционная зависимость уровня ДАД и ИМТ при дисрегуляции АД, по-видимому, объясняется наличием U-образной зависимости между этими показателями, т.е. дефицит МТ, как и ИзМТ, может выступать в качестве ФР развития АГ.
Клинически выраженная Т и $\backslash$ или Д у юношей обнаружена только у лиц с АГ, у девушек - во всех выделенных категориях, однако, у лиц со скрытой АГ достоверно чаще.

В ходе проспективных исследований получены доказательства того, что Д и другие психологические нарушения выступают в роли ФР СС3 атеросклеротического генеза. Поэтому многие авторы считают, что указанные психологические особенности должны рассматриваться в совокупности с признанными ФР ССЗ. Д рассматривается как неблагоприятный прогностический фактор течения уже развившихся СС3. По данным Simonsick E.M. et al., риск инсульта у пожилых больных АГ и выраженными симптомами Д в 2,3-2,7 раза выше, чем у больных АГ без Д. С другой стороны, Д, являясь независимым ФР СС3, может предрасполагать к развитию СС3. Возможными механизмами развития СС3, возникающего вследствие прямого влияния предшествующей Д, являются ДЛП, гиперкоагуляция, нарушение функции эндотелия, снижение активности иммунной системы, обусловленные гиперкортизолемией, повышением активности гипоталамо-гипофизарно-надпочечниковой системы.

Полученные данные свидетельствуют о наличии сопряженности между параметрами суточного профиля АД и особенностями личности индивидуума. Достоверные взаимосвязи выявлены для юношей и девушек со скрытой АГ и касаются показателей суточного ритма и нагрузочных индексов САД и ДАД днем и ночью, а также СГД АДн. Эти особенности, по всей видимости, обусловлены избыточным влиянием симпатического отдела вегетативной нервной системы на сердечно-сосудистую систему в течение сут., т.к. известно, что развитие Д сопровождается сдвигом нейровегетативного статуса в сторону симпатикотонии.

Таким образом, установлено, что ассоциации между основными факторами ССР и показателями, характеризующими АД, существуют уже в молодом возрасте у практически здоровых лиц. А при наличии того или иного варианта АГ сила этих связей возрастает и, кроме того, обнаруживаются новые взаимосвязи.

\section{Выводы}

Факторы ССР достаточно широко представлены среди студенческой молодежи. Курение, ИзМТ, тревожно-депрессивные расстройства выявлены в $15,8 \%, 9,8 \%$ и $6,8 \%$ случаев, соответственно. При этом у юношей они встречаются в 2-3 раза чаще, чем у девушек.

Сопоставление результатов офисного и амбулаторного методов оценки АД убеждают в преимущественном наличии у студентов лабильных форм АГ - ИОАГ $(10,7 \%)$ и скрытой АГ $(11,5 \%)$. 
Студенты с любым вариантом лабильной АГ, в сравнении со сверстниками-нормотониками характеризуются увеличением абсолютных значений корреляционных связей и появлением дополнительных связей между показателями, характеризующими АД и некоторыми факторами CCP.

\section{Литература}

1. Государственный доклад о состоянии здоровья населения Российской Федерации в 2002 году. Здравоохр Рос Фед 2004; $1: 3-20$

2. Оганов Р.Г. Профилактика сердечно-сосудистых заболеваний в России: успехи, неудачи, перспективы. Тер архив 2004; 6: 22-4

3. Мареев. В.Ю., Фомин И.В, Агеев Ф.Т. и др. Распространенность факторов риска среди больных артериальной гипертонией в Европейской части Российской Федерации. Ж Серд недост 2004; 6(28) т. 5: 282-5.

4. Шальнова С.А., Деев А.Д., Вихирева О.В. Распространенность артериальной гипертонии в России. Информированность, лечение, контроль. Профил забол укреп здор 2001; 2: 3-7.
Ассоциированность лабильной АГ с основными факторами ССР у молодого контингента обосновывает необходимость включения в гр. риска лиц с указанными формами повышения АД, что позволит оптимизировать существующие программы по укреплению здоровья студентов.

5. Шестерикова Н.В. Динамика распространенности артериальной гипертензии и ее связь с основными факторами риска. Кардиоваск тер профил 2003; 2(3): 356.

6. Betteridge DJ. In: Obesity and cardiovascular deseases. London 1998: 6-7.

7. Dyer AK, Eliot $\mathrm{P}$, Shipley $\mathrm{M}$, et al Body mass index and association of sodium and potassium with blood pressure in intersalt. Hypertention 1994; 23: 729-36.

8. European Cardiovascular Disease Statistics - British Heart Foundation and European Heart Network 2005.

9. European Guidelines on Cardiovascular Disease Prevention in Clinical Practice. Eur Heart J 2003; 24 (17): 1601-10.

10. Ludwig DS. Childhood and Obesity - The Shape of Things to Come. N Engl J Med 2007; 357: 23-5. 